\title{
Modern pollen-vegetation relationship based on discriminant analysis across an altitudinal transect on Gongga Mountain, eastern Tibetan Plateau
}

\author{
LI Quan ${ }^{1,2 *}$, GE QuanSheng ${ }^{1} \&$ TONG GuoBang ${ }^{3}$ \\ ${ }^{1}$ Institute of Geographic Sciences and Natural Resources Research, Chinese Academy of Sciences, Beijing 100101, China; \\ ${ }^{2}$ Key Laboratory of Tibetan Environmental Changes and Land Surface Processes, Chinese Academy of Sciences, Beijing 100101, China; \\ ${ }^{3}$ Institute of Hydrogeology and Environmental Geology, Chinese Academy of Geological Sciences, Shijiazhuang 050061, China
}

Received April 12, 2012; accepted April 18, 2012; published online June 17, 2012

\begin{abstract}
Quantitative relationship between modern pollen assemblage and altitudinal vegetation belt is crucial for the reconstruction of paleovegetation in the mountain regions. Modern pollen analysis on 70 topsoil samples was conducted across an altitudinal transect (1100-4500 m) on the eastern slope of Gongga Mountain in the eastern Tibetan Plateau with an elevation interval of $50 \mathrm{~m}$. Distributions of major pollen types along the transect indicated a weak correlation between Pinus pollen and the elevation. Distributions of Picea and Abies pollen (percentage sum of 2\%-8\%) could fairly indicate the elevation range of 2700-3700 m, as well as the subalpine dark coniferous forest and the timberline in the region. High percentage intervals of alpine types of Ericaceae, Cupressaceae and Cyperaceae were correlated to the high-elevation regions $(3700-4500 \mathrm{~m})$ dominated by alpine shrub meadow and alpine meadow. Seven altitudinal vegetation belts on the eastern slope of Gongga Mountain were well defined by discriminant analysis conducted on the modern pollen assemblages, as reflected by high values of probability of modern analog. Most of the modern pollen assemblages (88.5\%) were typical for the vegetation types at their sampling locations. Thus, the relationship between the modern pollen assemblages and vegetation across the altitudinal transect based on discriminant analysis can be applied to the quantitative reconstruction of paleovegetation changes in the mountain regions of the eastern Tibetan Plateau.
\end{abstract}

modern pollen assemblage, altitudinal vegetation belt, discriminant analysis, Gongga Mountain, Tibetan Plateau

Citation: Li Q, Ge Q S, Tong G B. Modern pollen-vegetation relationship based on discriminant analysis across an altitudinal transect on Gongga Mountain, eastern Tibetan Plateau. Chin Sci Bull, 2012, 57: 4600-4608, doi: 10.1007/s11434-012-5236-6

The Tibetan Plateau (TP) with an average elevation of 4000 $\mathrm{m}$ a.s.l. (above sea level) is featured with unique alpine vegetation covers, from subtropical forest in the southeastern margins, to alpine steppe and meadow in the interior plateau, and to alpine desert in the northwestern region [1]. In recent years, paleovegetation changes in the TP have attracted more and more attentions for the vulnerabilities of alpine vegetation to the environmental changes [2-7] and human activities [8,9]. Among numerous proxies, fossil pollen assemblage have become one of the major archives for the reconstructions of paleovegetation and paleoclimate in the TP [3-7,10-19]. Based on the modern pollen investigations in the TP, the sensitive responses of vegetation to

*Corresponding author (email: quanli_cas@163.com) the climate changes have been reconstructed by the fossil pollen records with successive sedimentation and high resolution [12-19]. Most of these studies were focused on the vegetation changes of the horizontal vegetation zones in the northeastern [13-15,19], central-southeastern [3-5,10,16] and western TP [11]. Accordingly, previous modern pollen investigations have been limited to explore the relationships between surface pollen spectra, vegetation and climate conditions in the eastern regions [19,20], the western plateau [21], and the whole surface of the TP on a large scale $[8,12$, 17,22].

Due to the marked changes of meterorological and hydrological conditions over relatively short distances, mountainous vegetation is very vulnerable to climate changes on different time scales [23]. The changes of altitudinal vegeta- 
tion belts, diagnostic species, ecotones and timberline in mountain regions can reflect the climate changes sensitively [24], as documented by fossil pollen records [17,25-27]. Therefore, modern pollen assemblage and its quantitative relationship with contemporary altitudinal vegetation belt are of great importance for the quantitative interpretations of fossil pollen records, as well as the quantitative paleovegetation changes in response to climate variations in the mountain regions [27]. In the eastern margins of the TP, altitudinal vegetation belts consist of various vegetation types from subtropical forest to alpine shrub and meadow along the elevation gradient [1]. However, little is known about the modern pollen distributions in the mountain regions of the eastern plateau.

The Gongga Mountain is situated in the eastern TP $\left(101^{\circ} 30^{\prime}-102^{\circ} 10^{\prime} \mathrm{E}, 29^{\circ} 20^{\prime}-30^{\circ} 00^{\prime} \mathrm{N}\right)$ with an optimum elevation of $7556 \mathrm{~m}$ a.s.1. [28]. Modern vegetation on the eastern slope of Gongga Mountain is composed of integrated vegetation belts, from the valley arid shrub and grass vegetation, to subtropical evergreen forest and coniferous forest, and to alpine shrub and meadow [28]. The vertical distributions of vegetation in the region are mainly controlled by the humidity and temperature gradients related to elevation changes [29]. Vegetation investigation on the glacial forelands in this region suggested a rapid vegetation succession during the last 170 years, from bare land and herb community to the occupation of pioneer trees Salix-Hippophae-Populus, and to the climax community of Picea and Abies [30].

Here, a detailed modern pollen investigation is conducted on the eastern slope of Gongga Mountain to explore the elevational distributions of pollen indicators of diagnostic species and the timberline, and the quantitative relationships between modern pollen assemblages and altitudinal vegetation belts by using discriminant analysis [31]. The results of modern pollen-vegetation relationships along an elevation gradient in the region could provide modern analogue and information for the reconstructions of paleovegetation changes in the mountain regions of the eastern TP.

\section{Modern climate and vegetation}

The eastern slope of Gongga Mountain is characterized by a distinct environmental gradient from warm/dry conditions at low-elevation regions to cold/moisture environment at high-elevation slopes, due to the relative elevation difference of about $6500 \mathrm{~m}$ [28]. The mean annual temperature (MAT) is $12.2^{\circ} \mathrm{C}$, and mean annual precipitation (MAP) is about $1050 \mathrm{~mm}$ at $1640 \mathrm{~m}$, while the MAT decreases to $4^{\circ} \mathrm{C}$, and MAP increases to $1938 \mathrm{~mm}$ at $3000 \mathrm{~m}$ [28] (Figure 1).

Altitudinal vegetation belts on the eastern slope of Gongga Mountain are composed of valley arid shrub and grass vegetation belt, agro-forest vegetation, evergreen broadleaved forest, mixed coniferous and broad-leaved forest, subalpine dark coniferous forest, alpine shrub meadow, alpine meadow, and alpine sparse vegetation (Figure 1). Details of the altitudinal vegetation belts in the region are described as the following $[28,32,33]$.

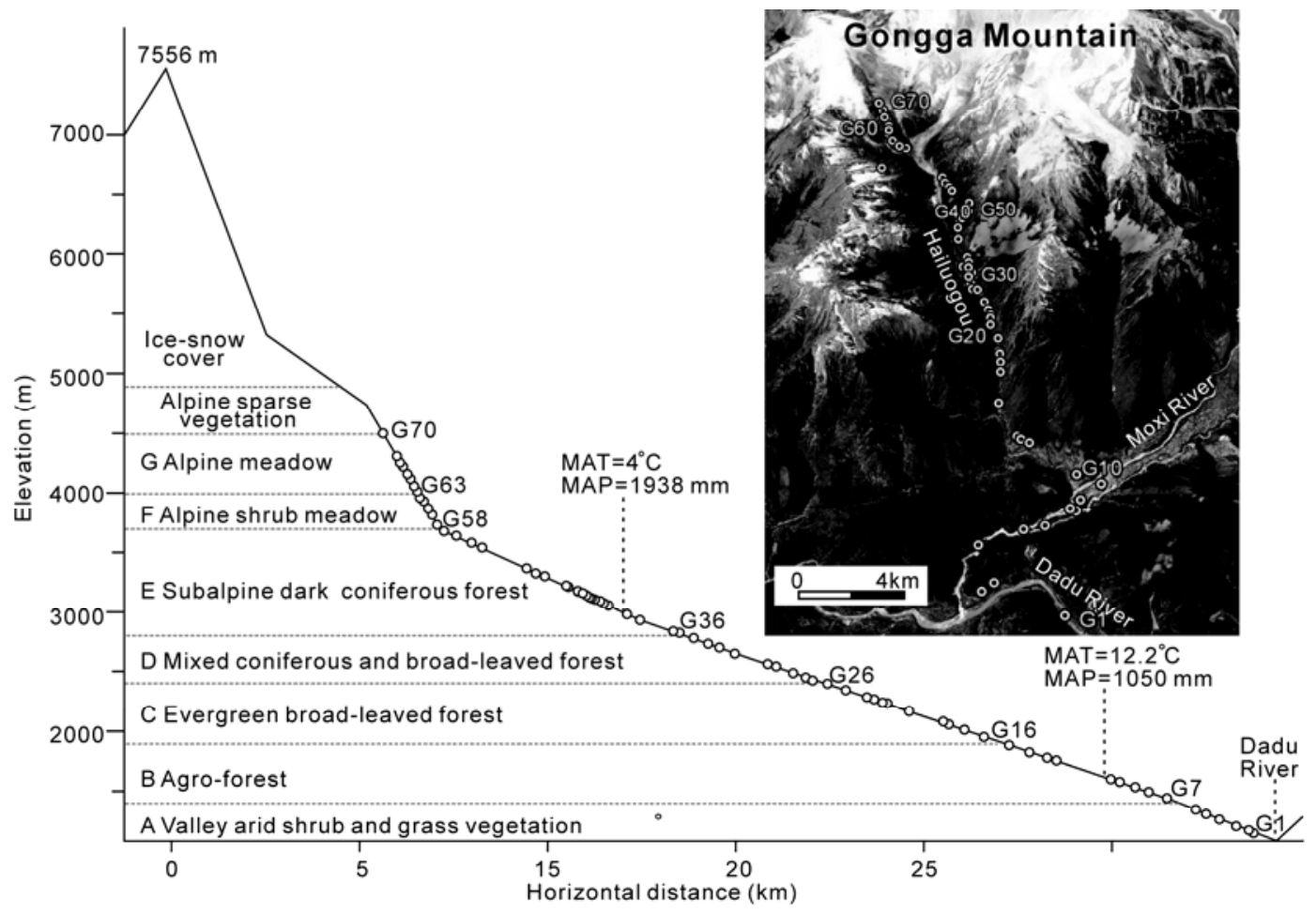

Figure 1 Sketch map of altitudinal vegetation belts and climatic observation data on the eastern slope of Gongga Mountain [28,32], and locations of modern pollen samples from G1 to G70 (indicated by circles). 
(i) Valley arid shrub and grass vegetation (elevation $<1400 \mathrm{~m}$ ), occupying the valley regions of Dadu River and Moxi River, mainly consists of Acacia and Sophora shrubs, and Andropogon, Heteropogon and Artemisia, with some pine forest of Pinus yunnanensis.

(ii) Agro-forest under intensive influence of human activity $(1400-1900 \mathrm{~m})$ is dominated by economic forests of Cyclobalanopsis, Cunninghamia lanceolate, Juglans acerba, Diospyros kaki, Morus, etc., and farm crops of rice, wheat and maize [32].

(iii) Evergreen broad-leaved forest $(1900-2400 \mathrm{~m})$ is mainly composed of Quercus engleriana, Lithocarpus cleistocarpus, Cinnanmonum, Phoebe chinensis, Osmanthus, etc.

(iv) Mixed coniferous and broad-leaved forest (2400$2800 \mathrm{~m}$ ) is dominated by various species of Tsuga and deciduous trees of Betula and Acer, with some Euptolea pleiospermum, Sorbus, Carpinus, patchy community of Pinus armandii and a few Picea brachytyla.

(v) Subalpine dark coniferous forest $(2800-3700 \mathrm{~m})$ is characterized by Picea brachytyla and Abies fabric, with patchy secondary forests of Betula, Salix and Sorbus, and some shrubs of Rhododendron and Bashania fangiana. Usually, Abies penetrates to the upper slopes (2800-3600 m) above Picea (2300-2800 m) on the eastern slope of Gongga Mountain [33].

(vi) Alpine shrub meadow $(3700-4000 \mathrm{~m})$ is mainly composed of shrub species of Rhododendron, and meadow of Kobresia and Festuca, with patchy shrubs of Sabina, Salix and Potentilla.

(vii) Alpine meadow $(4000-4500 \mathrm{~m}$ ) is dominated by various species of Kobresia, Potentilla and Festuca.

Besides, alpine sparse vegetation (4500-4900 m) occurs below the snow line, composed mainly of Saussurea, Soroseris, Arenaria, etc.

\section{Materials and methods}

In July 2004 and October 2005, modern pollen samples were collected at an average elevation interval of $50 \mathrm{~m}$ across the altitudinal transect from 1100 to $4500 \mathrm{~m}$ a.s.l. at Hailuogou, in the eastern slope of Gongga Mountain. In total, 70 topsoil samples $(0-2 \mathrm{~cm})$ from different altitudinal vegetation belts were analyzed palynologically, including 6 samples from valley arid shrub and grass vegetation, 9 from agro-forest vegetation, 11 from evergreen broad-leaved forest, 9 from mixed coniferous and broad-leaved forest, 22 from subalpine dark coniferous forest, 5 from alpine shrub meadow, and 8 from alpine meadow. These topsoil samples covered the major vegetation types on the eastern slope of Gongga Mountain [28,32,33] (Figure 1).

Topsoil samples were treated with a modified acetolysis procedure for palynological analysis, including $10 \% \mathrm{HCl}$, $5 \% \mathrm{KOH}, 40 \% \mathrm{HF}$, acetolysis treatments, and sieving with a 7- $\mu \mathrm{m}$ screen to remove clay-sized particles [34]. The average number of counted pollen and spores is 450 grains per sample. Pollen percentages were calculated based on the sum of all pollen and spores.

Discriminant analysis has been effectively applied to investigate the relationship between modern pollen assemblage and vegetation $[31,35,36]$. It is a statistical inference technique to seek for the combinations of variables, called discriminant functions $[31,36]$. These discriminant functions can be used to separate samples among the a priori groups, and to classify new samples with unknown group memberships into one of the a priori groups [36]. Here, we conducted a discriminant analysis by using software SPSS 10.0 [37] to evaluate whether modern pollen assemblages could quantitatively represent different vegetation types along an elevation gradient. First, modern pollen samples were divided into seven a priori groups (actual vegetation), in consistence with vegetation types at sampling locations (indicated from A to G, Figure 2). Then percentage data of major pollen types were applied to establish the discriminant functions, and then the samples were classified into predicted vegetation groups. Based on the comparisons between a priori groups and predicted groups, two indices were introduced to quantitatively interpret the results. The one "probability of modern analog" represented the similarity between pollen assemblages and predicted vegetation groups, determined by the chi-square distance between a sample and its predicted group centroid defined by the discriminant functions. Another index "vegetation zonal index" (VZI) was converted from probabilities of predicted group membership between the first predicted and the second most probable group [31]. Detailed procedures and interpretations followed the published literatures $[31,35,36]$.

\section{Results}

\subsection{Modern pollen assemblages along an altitudinal transect}

A total of 145 pollen types were identified in the modern pollen assemblages from the altitudinal transect on the eastern slope of Gongga Mountain. The most abundant arboreal pollen types mainly included Pinus, Abies, Picea, Tsuga, Quercus (evergreen), Betula, Alnus, Corylus, Castanea, Quercus (deciduous), Carpinus, Juglans, Morus, Ulmus, etc. Shrub pollen types mainly included Salix, Cupressaceae, Ericaceae, etc. Herb pollen types mainly included Poaceae, Artemisia, Cyperaceae, Chenopodiaceae, Cruciferae, Fabaceae, Labiatae, Ranunculaceae, Thalictrum, Polygonum, Solanaceae, Androsace, Arenaria, etc. Modern pollen assemblages showed marked differences between various altitudinal vegetation belts (Figure 2).

(i) In the valley arid shrub and grass belt (G1-G6), modern pollen assemblages are dominated by Pinus (mean 


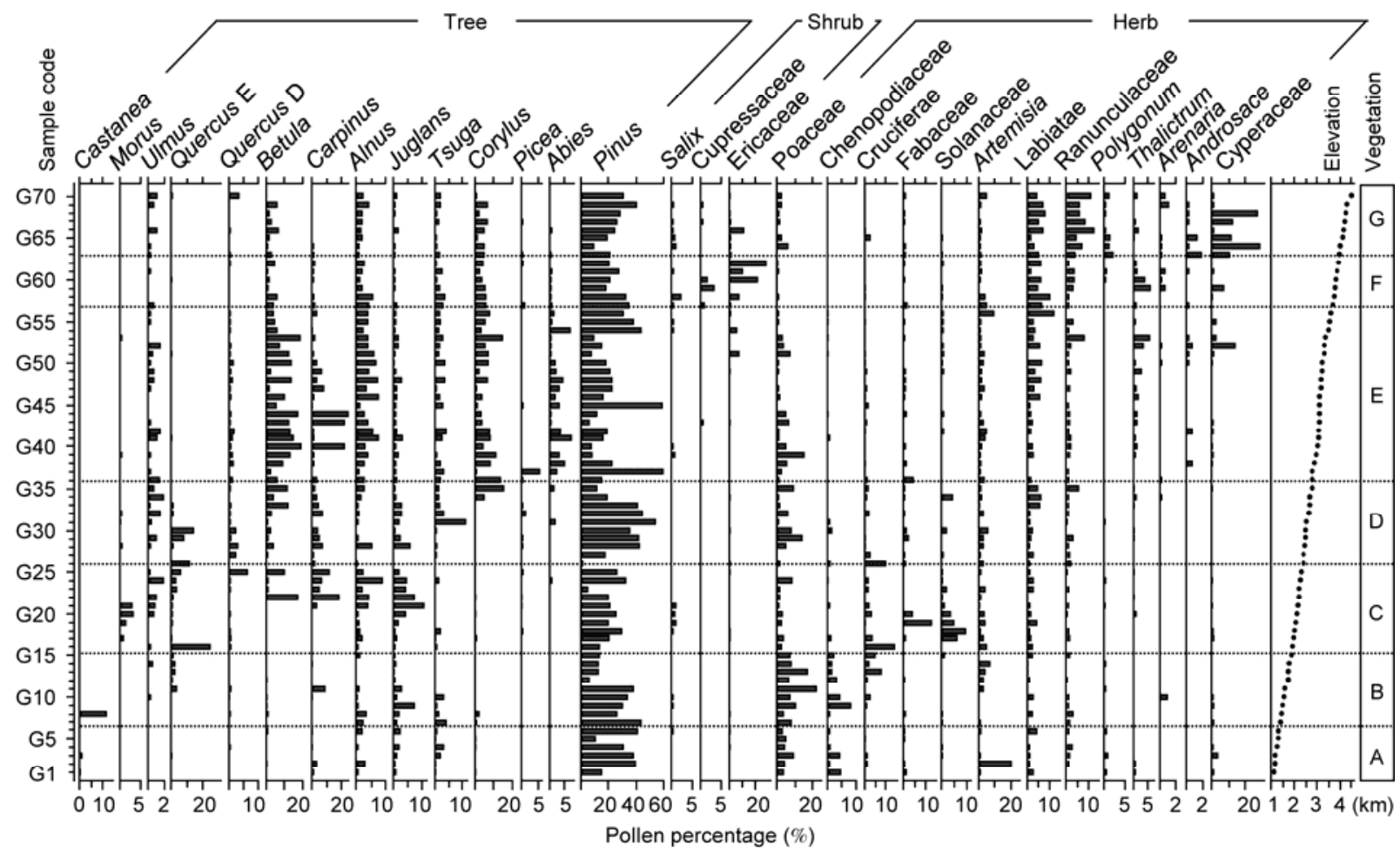

Figure 2 Pollen percentage diagram of topsoil samples across the altitudinal transect from 1000 to $4500 \mathrm{~m}$ on the eastern slope of Gongga Mountain, eastern Tibetan Plateau. Only selected taxa were shown. Quercus E and Quercus D indicated the evergreen and deciduous types of Quercus pollen, respectively. Please see Figure 1 for correspondence between samples and vegetation belts from vegetation type A to G.

$29.8 \%$ ), Poaceae (5.6\%), Artemisia (up to 20.4\%, mean $4.4 \%$ ), Chenopodiaceae (2\%), with some other herb types $(<2 \%)$ such as Labiatae, Cyperaceae and Ranunculaceae. Other arboreal types are very few in the vegetation belt.

(ii) Modern pollen assemblages from the agro-forest vegetation (G7-G15) are characterized by the highest mean percentages of Poaceae (up to 22.3\%, mean 10.7\%), Chenopodiaceae (up to $8.5 \%$, mean $2.7 \%$ ) and Cruciferae (up to $8.7 \%$, mean $2.6 \%$ ), and a percentage peak of Castanea (up to $12.3 \%)$. Pinus (24.8\%) and Artemisia (2.5\%) are common.

(iii) Modern pollen assemblages from evergreen broadleaved forest (G16-G26) are mainly composed of arboreal types, such as evergreen Quercus (up to $26 \%$, mean $5.4 \%$ ), Juglans (up to $11.4 \%$, mean $3.7 \%$ ), Alnus (up to $9.4 \%$, mean $2.7 \%$ ) and Morus (up to 3\%). Pinus (20.2\%) and Betula $(3 \%)$ are common arboreal types.

(iv) In the mixed coniferous and broad-leaved forest, modern pollen assemblages (G27-G35) are characterized by percentage peaks of Tsuga (up to $11.6 \%$, mean $2.7 \%$ ), deciduous Quercus (up to 3.4\%), and high proportions of $\mathrm{Pi}$ nus (35\%), with abundant Betula (5\%) and Carpinus (4.5\%). Juglans and Alnus are common arboreal types.

(v) In the subalpine dark coniferous forest, modern pollen assemblages (G36-G57) are featured by abundant Picea (up to 5.8\%) and Abies (up to $7.4 \%$, mean 2.6\%). Pinus (23.6\%), Betula (10.1\%) and Tsuga $(2.2 \%)$ are common.
Pollen percentages of Ericaceae (1.1\%), Labiatae (3.6\%), Cyperaceae (1.6\%), Ranunculaceae (1.9\%) and Thalictrum $(1.2 \%)$ begin to increase in the coniferous forest belt, whereas Quercus, Carpinus and Poaceae pollen markedly reduce towards the upper slope.

(vi) Modern pollen assemblages from the alpine shrub meadow (G58-G62) are most characterized by abundant shrub types of Ericaceae (up to $29.8 \%$, mean $14.4 \%$ ), $\mathrm{Cu}-$ pressaceae (up to $3.4 \%$, mean 1.2\%) and Salix (up to $2.7 \%$ ), as well as herb types of Labiatae (6\%) and Thalictrum (2.6\%). Pinus pollen usually takes up about one quarter of the total pollen sum. Cyperaceae $(2.2 \%)$ and Ranunculaceae (2.9\%) are common herb types.

(vii) In the alpine meadow, modern pollen assemblages (G63-G70) are characterized by the high percentages of Cyperaceae (up to $29.1 \%$, mean $12.5 \%$ ) and Ranunculaceae (up to $12.9 \%$, mean $7.9 \%$ ). Pinus (25.7\%), Poaceae (2.7\%), Labiatae $(5.6 \%)$, Androsace $(<1 \%)$ and Arenaria $(<1 \%)$ are common.

\subsection{Discriminant analysis on modern pollen assemblages}

Percentage data of 30 major pollen types as shown in Figure 2 (more than $2 \%$ at least in one sample and of ecological importance) were used for the discriminant analysis of topsoil samples on the eastern slope of Gongga Mountain. 
Seven major vegetation types, from the valley arid shrubgrass vegetation (Group A) to alpine meadow (Group G) along the elevation gradient, were respectively assigned values from 1 to 7 as their VZI in advance. Accordingly, samples classified to valley arid shrub-grass vegetation should have VZI ranging from 0.5 to 1.5 , agro-forest vegetation from 1.5 to 2.5 , evergreen broad-leaved forest from 2.5 to 3.5 , and so on [31].

The results of discriminant analysis show that $88.5 \%$ (62 out of 70) of the samples were correctly classified into their actual vegetation groups (Table 1). The samples of valley arid shrub-grass vegetation (Group A), subalpine dark coniferous forest (Group E, except for one sample G36), alpine shrub meadow (Group F) and alpine meadow (Group $\mathrm{G})$ are the most distinct from samples of other vegetation types, according to the first two discriminant functions which accounts for $72 \%$ of the total variance (Figure 3). VZI values of samples from these four vegetation groups were respectively plotted into the value ranges of the actual vegetation types at the sampling locations (Figure 4).

However, group centroids of Group B, C and D were plotted close to each other to some extent (Figure 3). Consequently, a few samples of these groups were misclassified to their vicinity groups, including G8 and G14 from agro-forest vegetation, G24, G25 and G26 from evergreen broad-leaved forest, G30 and G34 from mixed coniferous and broad-leaved forest (Table 1, Figure 4). This is also demonstrated by their low values of probability of modern analog $(<0.5)$ and abnormal VZI values (Figure 4).

\section{Discussion}

\subsection{Elevational distributions of major pollen types}

Modern pollen assemblages from the eastern slope of Gongga Mountain indicate that pollen distribution patterns along the elevation gradient vary among different pollen types (Figure 5).

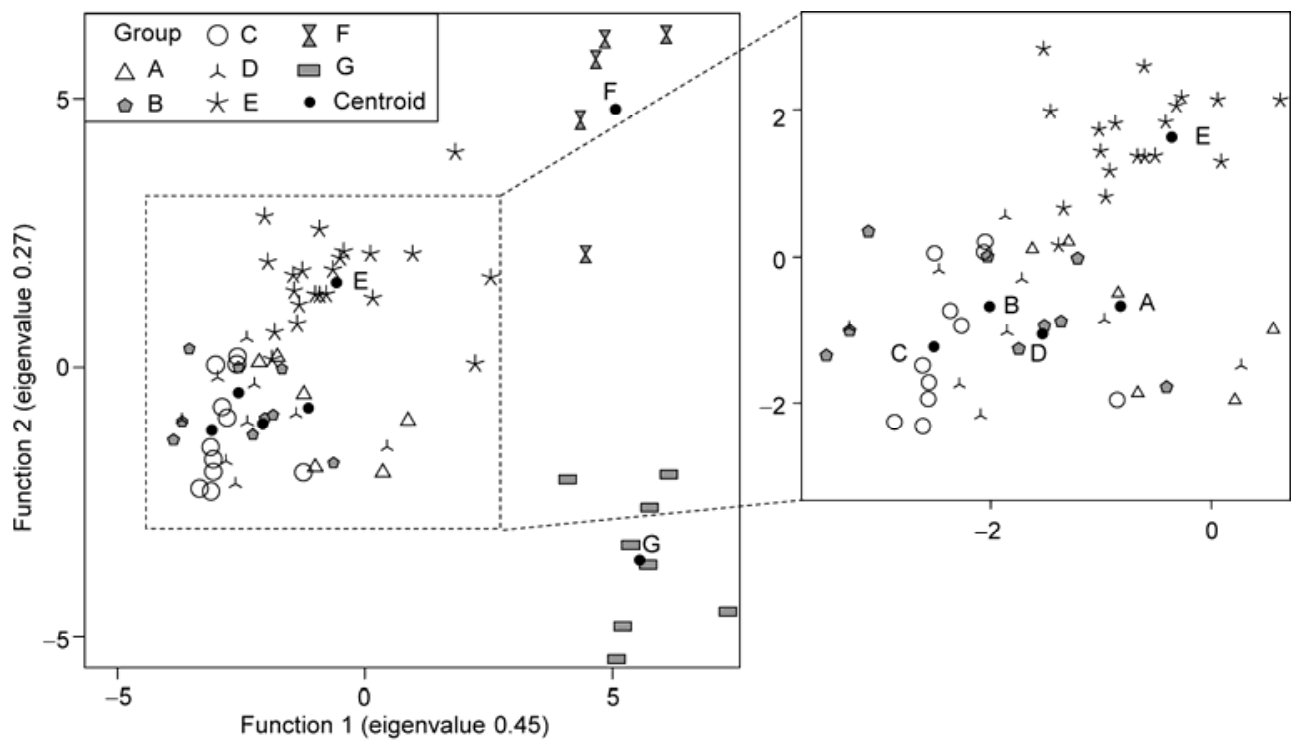

Figure 3 Predicted groups plotted against discriminant functions 1 and 2 for topsoil samples on the eastern slope of Gongga Mountain (see Figure 1 for vegetation types of Group A to G).

Table 1 Summary of discriminant analysis results of modern pollen assemblages on the eastern slope of Gongga Mountain

\begin{tabular}{ccccccccc}
\hline \multirow{2}{*}{ Actual group } & No. of samples & \multicolumn{7}{c}{ Predicted group } \\
\cline { 2 - 9 } & A & B & C & D & E & F & G \\
\hline A & 6 & $6^{\text {a) }}$ & 0 & 0 & 0 & 0 & 0 & 0 \\
B & 9 & 2 & $7(77.8 \%)$ & 0 & 0 & 0 & 0 & 0 \\
C & 11 & 0 & 0 & $8(72.7 \%)$ & $3(27.3 \%)$ & 0 & 0 & 0 \\
D & 9 & 0 & 0 & $2(22.2 \%)$ & $7(77.8 \%)$ & 0 & 0 & 0 \\
E & 22 & 0 & 0 & 0 & $1(4.5 \%)$ & $21(95.5 \%)$ & 0 & 0 \\
F & 5 & 0 & 0 & 0 & 0 & 0 & 0 & 0 \\
G & 8 & 0 & 0 & 0 & 0 & 0 & 0 & 0 \\
\end{tabular}




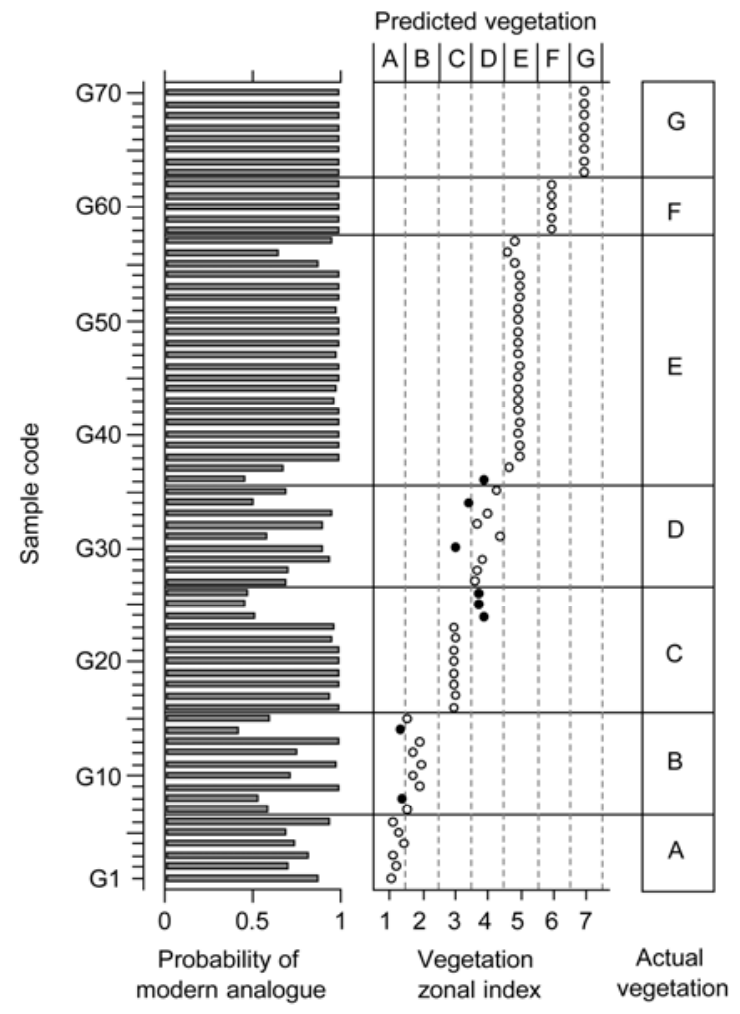

Figure 4 Comparisons between predicted vegetation groups of discriminant analysis and actual vegetation types at sampling locations on the eastern slope of Gongga Mountain. Misclassified samples were indicated by solid circles.

Pinus pollen (mean percentage of $25.6 \%$ ), the predominant arboreal type in most samples, distributes more or less evenly across the altitudinal transect (Figures 2 and 5). On the eastern slope of Gongga Mountain, three pine species mainly distribute in the medium-elevation regions, such as Pinus yunnanensis (elevation range of 1100-1800 m, MAT of $11.5-18^{\circ} \mathrm{C}$, MAP of 800-1200 mm), P. armandii and $P$. densata (2200-2600 m, MAT of $3-11^{\circ} \mathrm{C}$, MAP of 600 $1500 \mathrm{~mm}$ ) [38]. Only pine forest of $P$. armandii can penetrate to the high elevations of 2900-3500 m on the western slope of Gongga Mountain [33]. However, abundant Pinus pollen grains are commonly found across the whole transect. It accounts for more than $27 \%$ in the low-elevation regions (1100-2600 m) where pine forests occur, and for 8\%-59\% in the high elevations above $2600 \mathrm{~m}$. Even in the upmost part of the transect (3700-4500 m), Pinus pollen accounts for $10 \%-41 \%$ of the total pollen sum.

The high percentages of Pinus pollen across the altitudinal transect is probably caused by the strong upward wind transport into the high-elevation slope and an exotic input to the low-elevation region [39], as well as pollen morphological feature of air saccus and relatively low settling speeds [40]. In the southern TP, previous modern pollen investigation suggested that the high percentages of Pinus pollen exceeding $30 \%$ could indicate an occupation of pine forest [41]. However, our results reveal that Pinus pollen exhibits a weak correlation with the elevation or the altitudinal vegetation belt due to long-distance dispersal by valley winds (Figure 3). Therefore, distribution of Pinus pollen could not necessarily indicate a certain elevation range or the pine forest on the mountain regions of the eastern TP.

It seems that the proportions of Abies and Picea (2\%$8.5 \%$ at the elevations of 2700-3700 m) in our modern pollen spectra are much lower than those on the interior TP (as high as 26\%) [40], and Changbai Mountain in the northeast China ( $>25 \%$ ) [42]. Previous pollen investigations in Xinjiang [43] and Inner Mongolia [44] have indicated that pollen percentages of Picea could reach as high as 30\%-80\% in the spruce forests. On the eastern slope of Gongga Mountain, the high biodiversity [29] and a large amount of exotic input of Pinus pollen may be the main reasons for the low occurrences of Picea and Abies pollen. However, the distribution of Abies and Picea pollen clearly exhibit high correlation with the elevation (Figure 5). Relative high percentages of Abies and Picea (2\%-8.5\%) are restricted to the elevation range from $2700-3700 \mathrm{~m}$, in which subalpine fir and spruce forests dominate (Figure 5). Besides, an optimum percentage of Picea (5.7\%) occurs at the elevation of $2800 \mathrm{~m}$, lower than the elevation range of high percentages of Abies (>5\%, 2900-3500 m) (Figure 2). This probably reflects the ecological differences between spruce (MAT of 5- $8^{\circ} \mathrm{C}$, MAP of $1500-1600 \mathrm{~mm}, 2400-2800 \mathrm{~m}$ ) and fir forest (MAT of $1-4.5^{\circ} \mathrm{C}$, MAP of $1500-1700 \mathrm{~mm}, 2800-3600$ $\mathrm{m})$ on the eastern slope of Gongga Mountain [33].

Although Tsuga and Betula pollen show high percentages at the elevations of mixed coniferous and broad-leaved forest, they could also disperse upward by the valley winds, but to a lesser extent compared with that of Pinus. High percentages of Quercus pollen ( $>10 \%$, sum of evergreen and deciduous types) are concentrated within the elevations of 2000-2600 m. However, it should be noticed that anthropogenic forestry has strongly altered the oak forests on the Gongga Mountain [29]. For instance, some forests of Quercus variabilis, $Q$. acutissima and $Q$. monimotricha (1600-1800 m), Q. longispica (2400-3400 m), Q. pannosa and $Q$. gilliana (3000-3900 m) have degraded to coppice forest and shrub after the intensive fuelwood consumption [38]. Ericaceae $(>10 \%)$, Cupressaceae $(>1 \%)$ and Cyperaceae pollen $(>10 \%)$, as typical alpine pollen types, show high percentages only at the elevations of 3700-4500 m with peaks at around $4000 \mathrm{~m}$. Distributions of Poaceae pollen exhibit confusing relationship with the elevation, probably attributed to intensive anthropogenic influences on the vegetation [32].

In summary, the elevational distributions of major pollen types across the altitudinal transect on the eastern slope of Gongga Mountain provide implications for the reconstruction of paleovegetation change in the mountain regions. Pinus pollen shows a weak correlation with the elevation, and its distribution could not indicate the elevation range of pine forest in the region. The distributions of some other 

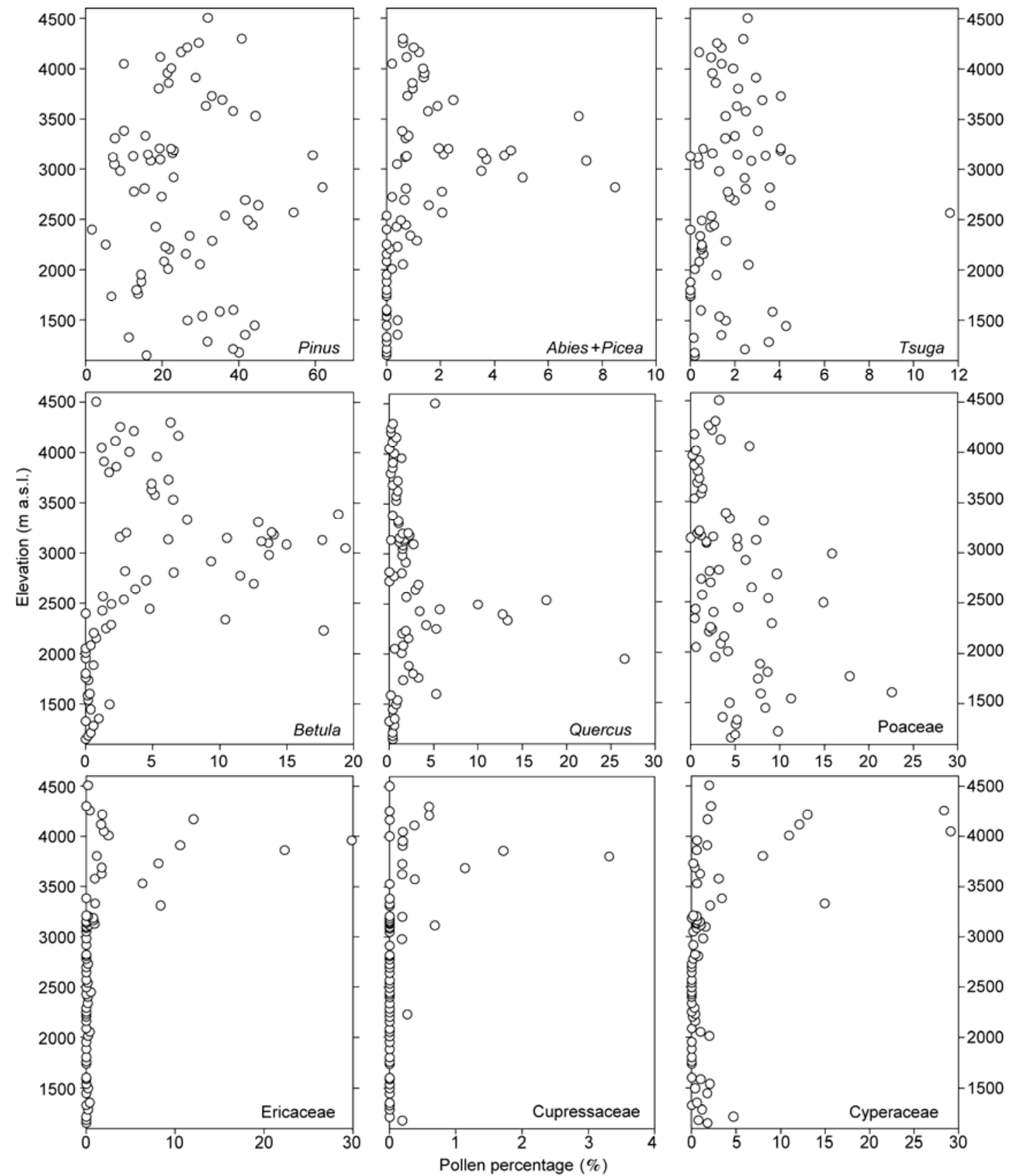

Figure 5 Elevational distributions of major pollen types in the topsoil samples from the eastern slope of Gongga Mountain, eastern Tibetan Plateau.

coniferous (Tsuga) and broad-leaved pollen types (Betula and Quercus) as well as Poaceae have no persistent indications to the elevation, due to influences from either valley winds or human activities. Distributions of Picea and Abies pollen show strong correlation with the elevation. Their sum percentage of $2 \%-8 \%$ could well indicate the elevation range of 2700-3700 m, as well as the distribution of subalpine dark coniferous forest $(2800-3700 \mathrm{~m})$ and the elevation of timberline $(3700 \mathrm{~m})$ on the eastern slope of Gongga Mountain [32]. Distributions of Ericaceae, Cupressaceae and Cyperaceae could approximately indicate the high ele- vations in which alpine shrub and alpine meadow dominate.

\subsection{Quantitative relationships between modern pollen assemblages and altitudinal vegetation belts}

Based on the quantitative results of discriminant analysis conducted on 70 topsoil samples, major vegetation types across the altitudinal transect on the eastern slope of Gongga Mountain can be distinguished by their modern pollen assemblages (Table 1, Figure 4).

In the valley arid shrub-grass vegetation belt $(<1400 \mathrm{~m})$, 
modern pollen assemblages are featured by abundant Poaceae, Artemisia and Chenopodiaceae. The mean VZI value (1.2) and high probability of modern analog of the samples (0.8) suggest a good representative of modern pollen assemblages to the valley arid shrub-grass vegetation.

Although vegetation in the agro-forest belt (1400-1900 $\mathrm{m}$ ) is intensively influenced by human activities, results of discriminant analysis can approximately differentiate its modern pollen assemblages from those of other vegetation types, as indicated by a mean VZI of 1.7 and moderate probability of modern analog of 0.7 . This could be probably denoted by the abundance of Poaceae, Chenopodiaceae, Cruciferae and Castanea pollen related to farm crops and economic forests [29].

About $73 \%$ of the samples from evergreen broad-leaved forest (1900-2400 m), and 78\% of the samples from mixed coniferous and broad-leaved forest (2400-2800 m) are correctly defined to their actual vegetation types, both with the probability of modern analog of 0.7. However, some samples located close to the boundaries of vegetation belts are misclassified into the vicinity vegetation as suggested by low probability of modern analog $(<0.5)$, reflecting the vegetation transition at the sampling locations [31] (Figure 4).

High probability of modern analog (0.9) and a mean VZI value of 4.9 demonstrate the fair representative of modern pollen assemblages to the dark coniferous forest (2800$3700 \mathrm{~m}$ ). This is also indicated by the high percentages of Picea and Abies pollen within the coniferous forest belt.

Modern pollen assemblages from the alpine shrub meadow (3700-4000 m) and alpine meadow (4000-4500 m) distinctly reflect their source vegetation, as suggested by the high probabilities of modern analog close to 1 and accurate VZI values in the results of discriminant analysis.

In summary, seven major vegetation belts on the eastern slope of Gongga Mountain are well defined by discriminant analysis. Most of the modern pollen assemblages are typical for their source vegetation types along the elevation gradient, as reflected by the high value of probability of modern analog (mean 0.8) and high proportion of samples classified correctly $(88.5 \%)$.

\section{Conclusions}

Modern pollen investigations are conducted across an altitudinal transect from 1100-4500 m on the eastern slope of Gongga Mountain in the eastern TP. Relationships of modern pollen-altitudinal vegetation belts have been explored based on the elevational distributions of major pollen types and discriminant analysis on modern pollen spectra of 70 topsoil samples at an elevation interval of $50 \mathrm{~m}$. The main conclusions are summarized below.

(i) Major pollen types have different distribution patterns along the elevation gradient. Distribution of Pinus pollen exhibits a weak correlation with the elevation, and thus could not indicate elevation range of pine forest on the Gongga Mountain. Distributions of Picea and Abies pollen (sum 2\%-8\%) show good correlation with the elevation range of 2700-3700 m, and implications for the distributions of subalpine dark coniferous forest and the timberline. Alpine pollen types of Ericaceae, Cupressaceae and Cyperaceae could be the indicators for the high elevations of $3700-4500 \mathrm{~m}$.

(ii) Seven altitudinal vegetation belts on the eastern slope of Gongga Mountain can be well distinguished by discriminant analysis conducted on the modern pollen assemblages. The quantitative relationship between modern pollen assemblages and altitudinal vegetation belts could be used to reconstruct paleovegetation changes in the mountain regions of the eastern TP.

This work was supported by the National Natural Science Foundation of China (41102221 and 41071131), the National Basic Research Program of China (2005CB422002), the Open Research Fund of Key Laboratory of Tibetan Environmental Changes and Land Surface Processes, Chinese Academy of Sciences (TEL 201205) and the China Postdoctoral Science Foundation (20110490572). The authors thank the editor and two anonymous reviewers for helpful revisions. We are grateful to Wang $\mathrm{Luo}, \mathrm{Li}$ Yumei, Wang Guoan and Xu Deke for field assistance, and Linda Perry for language correction.

1 Tibetan Investigation Group. Vegetation of Xizang (Tibet) (in Chinese). Beijing: Science Press, 1988

2 Ni J. A simulation of biomes on the Tibetan Plateau and their responses to global climate change. Mt Res Dev, 2000, 20: 80-89

3 Tang L Y, Shen C M, Liu K B, et al. Climatic changes in the Southeastern Qinghai-Tibetan Plateau during the Last Glacial Maximum-Pollen records from Southeastern Tibet (in Chinese). Sci China Ser D-Earth Sci, 2004, 34: 436-442

4 Lu H Y, Wang S M, Wu N Q, et al. A new pollen record of the last 2.8 Ma from the Co Ngoin, central Qinghai-Xizang (Tibetan) Plateau. Sci China Ser D-Earth Sci, 2001, 44 (Suppl): 292-300

5 Shen C M, Liu K B, Morrill C, et al. Ecotone shift and major droughts during the mid-late Holocene in the central Tibetan Plateau. Ecology, 2008, 89: 1079-1088

6 Herzschuh U, Birks H J B, Ni J, et al. Holocene land-cover changes on the Tibetan Plateau. Holocene, 2009, 20: 91-104

7 Zhao Y, Yu Z C, Liu Z J, et al. Late Holocene vegetation and climate oscillations in the Qaidam Basin of the northeastern Tibetan Plateau. Quat Res, 2010, 73: 59-69

8 Miehe G, Miehe S, Schlütz F, et al. Palaeoecological and experimental evidence of former forests and woodlands in the treeless desert pastures of Southern Tibet (Lhasa, A.R. Xizang, China). Palaeogeogr Palaeoclimatol Palaeoecol, 2006, 242: 54-67

9 Miehe G, Miehe S, Kaiser K, et al. How old is pastoralism in Tibet? An ecological approach to the making of a Tibetan landscape. Palaeogeogr Palaeoclimatol Palaeoecol, 2009, 276: 130-147

10 Sun X J, Du N Q, Chen Y S, et al. Holocene palynological records in Lake Selincuo, northern Xizang (Tibet) (in Chinese). Acta Bot Sin, 1993, 35: 943-950

11 Van Campo E, Cour P, Hang S X. Holocene environmental changes in Bangong Co basin (Western Tibet). Part 2: The pollen record. Palaeogeogr Palaeoclimatol Palaeoecol, 1996, 120: 49-63

12 Shen C M. Millennial-scale variations and centennial scale events in the Southwest Asian monsoon: Pollen evidence from Tibet. Dissertation for the Doctoral Degree. Baton Rouge: Louisiana State University, 2003

13 Shen C M, Tang L Y, Wang S M, et al. Pollen records and time scale 
for the RM core of the Zoige Basin, northeastern Qinghai-Tibetan Plateau. Chin Sci Bull, 2005, 50: 553-562

14 Zhao Y, Yu Z C, Chen F H, et al. Holocene vegetation and climate history at Hurleg Lake in the Qaidam Basin, northwest China. Rev Palaeobot Palynol, 2007, 145: 275-288

15 Herzschuh U, Kramer A, Mischke S, et al. Quantitative climate and vegetation trends since the late glacial on the northeastern Tibetan Plateau deduced from Koucha Lake pollen spectra. Quat Res, 2009, 71: $162-171$

16 Tang $\mathrm{L} \mathrm{Y}$, Shen $\mathrm{C} \mathrm{M}, \mathrm{Li} \mathrm{C} \mathrm{H}$, et al. Pollen inferred vegetation and environment changes in central Tibetan Plateau since 8200 a BP. Sci China Ser D-Earth Sci, 2009, 52: 1104-1114

17 Lu H Y, Wu N Q, Liu K B, et al. Modern pollen distributions in Qinghai-Tibetan Plateau and the development of transfer functions for reconstructing Holocene environmental changes. Quat Sci Rev, 2011, 30: 947-966

18 Shen C M, Liu K B, Tang L Y, et al. Quantitative relationships between modern pollen rain and climate in the Tibetan Plateau. Rev Palaeobot Palynol, 2006, 140: 61-77

19 Herzschuh U, Birks H J B, Mischke S, et al. A modern pollen-climate calibration set based on lake sediments from the Tibetan Plateau and its application to a Late Quaternary pollen record from the Qilian Mountain. J Biogeogr, 2010, 37: 752-766

20 Zhao Y, Herzschuh U. Modern pollen representation of source vegetation in the Qaidam Basin and surrounding mountains, northeastern Tibetan Plateau. Veget Hist Archaeobot, 2009, 18: 245-260

21 Cour P, Zheng Z, Duzer D, et al. Vegetational and climatic significance of modern pollen rain in northwestern Tibet. Rev Palaeobot Palynol, 1999, 104: 183-204

22 Yu G, Tang L Y, Yang X D, et al. Modern pollen samples from alpine vegetation on the Tibetan Plateau. Glob Ecol Biogeogr, 2001, 10: 503-519

23 Diaz H F, Grosjean M, Graumlich L. Climate variability and change in high elevation regions: Past, present and future. Clim Change, 2003, 59: 1-4

24 Song M H, Zhou C P, Ouyang H. Distributions of dominant tree species on the Tibetan Plateau under current and future climate scenarios. Mt Res Dev, 2004, 2: 166-173

25 Zhang Y, Kong Z C, Yan S, et al. Fluctuation of Picea timberline and paleo-environment on the northern slope of Tianshan Mountains during the Late Holocene. Chin Sci Bull, 2006, 51: 1747-1756

26 Kramer A, Herzschuh U, Mischke S, et al. Holocene treeline shifts and monsoon variability in the Hengduan Mountains (southeastern Tibetan Plateau), implications from palynological investigations. Palaeogeogr Palaeoclimatol Palaeoecol, 2010, 286: 23-41

27 Li Q, Lu H Y, Zhu L P, et al. Pollen-inferred climate changes and vertical shifts of alpine vegetation belts on northern slope of Nyainqentanglha Mountains (central Tibetan Plateau) since 8.4 kyr
BP. The Holocene, 2011, 21: 939-950

28 Zhong X H, Zhang W J, Luo J. The characteristics of the mountain ecosystem and environment in the Gongga Mountain Region. Ambio, 1999, 28: 648-654

29 Shen Z H, Fang J Y, Liu Z L, et al. Patterns of biodiversity along the vertical vegetation spectrum of the eastern aspect of Gongga Mountain (in Chinese). Acta Phytoecol Sin, 2001, 25: 721-732

30 Li X, Xiong S F. Vegetation primary succession on glacier foreland in Hailuogou, Mt. Gongga (in Chinese). Mt Res, 1995, 13: 109-115

31 Liu K B, Lam N S N. Paleovegetational reconstruction based on modern and fossil pollen data: An application of discriminant analysis. Ann Ass Am Geogr, 1985, 75: 115-130

32 Cheng G W, Luo J. Successional features and dynamic simulation of subalpine forest in the Gongga Mountain, China. Acta Ecol Sin, 2002, 22: $1049-1056$

33 Zhong X H, Wu N, Luo J, et al. Researches of the Forest Ecosystems on Gongga Mountain (in Chinese). Chengdu: Press of Chengdu University of Science and Technology, 1997

34 Fægri K, Iversen J. Textbook of Pollen Analysis. 4th ed. London: John Wiley \& Sons, 1989

35 Lynch E A. The ability of pollen from small lakes and ponds to sense fine-scale vegetation patterns in the Central Rocky Mountains, USA. Rev Palaeobot Palynol, 1996, 94: 197-210

36 Shen C M, Liu K B, Tang L Y, et al. Numerical analysis of modern and fossil pollen data from the Tibetan Plateau. Ann Ass Am Geogr, 2008, 98: 755-772

37 SPSS Inc. SPSS Base 10.0 for Windows User's Guide. Chicago, IL: SPSS Inc. 1999

38 Liu Z G. Vegetation of Gongga Mountain (in Chinese). Chengdu: Sichuan Science and Technology Press, 1985

39 Tong G B, Yang X D, Liu Z M, et al. Surface soil pollen distributions in the Yulong Mountain (in Chinese). Mar Geol Quat Geol, 2003, 23: 103-107

40 Lu H Y, Wu N Q, Yang X D, et al. Spatial pattern of Abies and Picea pollen distribution along the elevation gradient in the QinghaiTibetan Plateau and Xinjiang, China. Boreas, 2008, 37: 254-262

$41 \mathrm{Wu}$ Y S, Xiao J Y. A preliminary study on modern pollen rain of Zabuye Salt Lake area, Xizang (in Chinese). Acta Bot Yunnan, 1995, 17: $72-78$

42 Sun X J, Luo Y L, Tian J, et al. Pollen record of surface sediments from vertical forest zones of Changbai Mountains, northeast China and their relations to the modern vegetation. Acta Bot Sin, 2003, 45: 910-916

43 Yan S, Kong Z C, Yang Z J, et al. Seeking relationship between vegetation and Picea pollen in surface soils of Xinjiang, northeastern China (in Chinese). Acta Ecol Sin, 2004, 24: 2017-2023

$44 \mathrm{Li}$ W Y. On dispersal efficiency of Picea pollen (in Chinese). Acta Bot Sin, 1991, 33: 792-800

Open Access This article is distributed under the terms of the Creative Commons Attribution License which permits any use, distribution, and reproduction in any medium, provided the original author(s) and source are credited. 